\title{
Using online multiple choice questions with multiple attempts: A case for self-directed learning among tertiary students
}

\author{
Ng Wen Lee ${ }^{1}$, Wan Noor Farah Wan Shamsuddin ${ }^{2}$, Lim Chia Wei ${ }^{3}$, Muhammad Nur Adilin Mohd \\ Anuardi $^{4}$, Chan Swee Heng ${ }^{5}$, Ain Nadzimah Abdullah ${ }^{6}$ \\ ${ }^{1,2,3}$ Centre of Liberal Arts and Languages, INTI International University, Malaysia \\ ${ }^{4}$ Information Science and Engineering, Shibaura Institute of Technology, Japan \\ ${ }^{5,6}$ School of Education, Taylor's University, Malaysia
}

\begin{tabular}{l}
\hline \hline Article Info \\
\hline Article history: \\
Received Sep 8, 2020 \\
Revised Mar 4, 2021 \\
Accepted Apr 9, 2021 \\
\hline
\end{tabular}

\section{Keywords:}

Learning skill

Multiple attempts

Multiple choice questions

Online learning for learning

English

Self-directed learning

\begin{abstract}
Criticisms on multiple choice questions (MCQs) include the possibility of students answering MCQs correctly by guessing, and MCQs generally are said to fall short in cultivating independent learning skills, such as taking charge of their learning goals. Countering these common concerns, this research used online MCQ exercises with multiple attempts to investigate the experiences that drove students to become self-directed learners. In this research, 60 students completed two sets of online MCQ exercises with multiple attempts outside of classroom time for six weeks consecutively. Both focus group interviews and an online survey were conducted to investigate the experiences of using online MCQ exercise with multiple attempts in relation to the development of self-directed learning (SDL). The findings of the study showed that the criticisms may be unfounded. Data leads to the conclusion that the majority of the students do not just try to guess at the correct answers. Rather, many of them attempted the online MCQ exercises more than once to improve themselves indicating that they were interested in self-learning. Students also reported that they utilised search and inquiry skills that clearly showed motivated initiatives to plan how to overcome their weaknesses by independently looking for relevant resources, determine their own learning goals, and evaluate their own learning performance as a firm indicator of SDL development. Based on the findings, this study is able to refute the claim that MCQs are unable to cultivate independent learning skills.
\end{abstract}

This is an open access article under the CC BY-SA license.

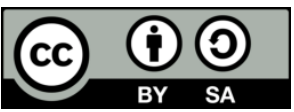

\section{Corresponding Author:}

$\mathrm{Ng}$ Wen Lee

Centre of Liberal Arts and Languages

INTI International University

Persiaran Perdana BBN, Putra Nilai, 71800 Nilai, Negeri Sembilan, Malaysia

Email: wenleeng@ymail.com

\section{INTRODUCTION}

The use of Learning Management System (LMS) such as Moodle and Blackboard has increased rapidly [1] in tandem with the growth of technology use in the classroom. Started as an online software that only enables educators to share course lectures to students, LMS has evolved to become an environment that supports flexible, personalized and collaborative learning [2]. A broad range of tools are now available in different LMS, including discussion board, wiki, blog, fill in the blanks, and multiple choice questions (MCQs), to name a few. At the university, much encouragement is given for inclusion of technology as part of the teaching and learning tools. 
Given the environment, researchers do have access to a variety of LMS. After much exploratory use, the researchers of this study had initially tried out an informal use of MCQs with multiple attempts. It was observed that students seem to be generally more motivated in their learning. This observation led to the embarking of a structured research investigation that took on the formal incorporation of the use of MCQs with multiple attempts into an English language course at the university with a view that LMS had been frequently criticized for being used ineffectively [3]. With this identification of a research gap, the objective was formulated to use the MCQs with multiple attempts as a learning strategy. The specific aim was to identify the extent the online MCQs with multiple attempts was able to motivate students to carry out selfstudy and engage in self-directed learning (SDL).

This research is considered significant in contributing to the state of knowledge concerning the use of MCQs. It is also providing empirical data on an online learning experience that could show improved learning and performance as successful outcomes of the implementation of a teaching strategy in an English language course.

Multiple choice questions (MCQs) have been widely used in both paper-based and online assessments for several reasons. They are economical and time efficient. Educators can include a broad range of topics in a single test using MCQs [4]-[7]. Paper-based MCQs can be marked quickly using automatic scanners or markers with minimal training [8], and online MCQs can also be marked automatically; thus saving time spent on marking [9], [10]. Another key feature of MCQs is their objective nature which purportedly avoids bias; hence contributing to greater reliability and standardization [4], [5], [7], [8], [11]. Due to these advantages, MCQs have often been used to evaluate the ability of large numbers of students within a short period of time. Despite these strong points, some educators view MCQs negatively.

One of the criticisms levelled at MCQs is the inherent weakness of guessing at the right answer. As a result, the ability as tested by MCQs is subject to doubt. The possibility of answering MCQs correctly through guessing is indeed a recognised weakness [5]. Besides, MCQs have often been criticized for only evaluating lower level cognitive skills and testing knowledge of isolated facts [4]. Such MCQs are said to encourage students to memorize facts, thereby showing little application of knowledge gained. Thus, students are not trained to apply what they have learned in novel situations, but only have to recall specific, independent facts to answer the tests [7]. The ability to recall knowledge (i.e., knowledge/remember) is considered the lowest level of the cognitive skills defined in Bloom's taxonomy [12], [13].

However, it is undeniable that remembering basic knowledge from each field of study is of extreme importance for students who are learning novices in their respective fields. Knowledge, which is at the base of Bloom's taxonomy, is considered as the ability to gather "the hard core of facts or information in each field of knowledge” [13, p. 63]. Facts must be used to exchange information, and Bloom, et al. [13] pointed out that these facts form the basic elements that students must remember in order to be well versed in their fields.

Some research has contended that MCQs are not only suitable for evaluating first level cognitive skills (knowledge/remember), but also the next two levels of cognitive skills, comprehension/understand and application/apply [14], [15]. Others have even affirmed that MCQs can competently assess the first four cognitive skill levels, including analysis/analyse [16], [17]. In short, the level of cognitive skills MCQs can assess is not limited to only the first level, knowledge/remember.

Moreover, students have been found to have positive attitudes about answering MCQs that are given as formative assessments before summative assessments, such as in class progress tests or exercises. To situate the use of MCQs in this study, there is a need to understand the differences between summative and formative assessments using this approach. McKenna [18] asserts that MCQs should not be used in summative assessments. Scouller [19] as well as Cobb, et al. [20] concluded that when MCQs were only used as summative assessments, the students employed mostly surface learning strategies. In addition, the students only aimed to complete the course successfully by rote memorization of concepts and knowledge [20]. Cobb, at el. [20] then concluded that the high-stakes summative assessments using MCQs appeared to pressure students to resort to the use of surface learning strategies. While these weaknesses are recognised in the use of MCQs in summative testing, this research however, adopts a formative orientation in the use of MCQs. Students are not put in a summative test situation and the allowance of multiple attempts is a significant feature that points to positive impact in cultivating independent and self-paced learning.

Dalziel and Gazzard [21] reported that when online MCQs were provided to students for practice before formal assessments, they had responded positively. Responses from student evaluations indicated that both self-teaching and self-testing took place when students answer online MCQs as formative assessments. Thus, Dalziel and Gazzard [21] asserted that online MCQ practice before formal assessments encourages students to self-learn and has the potential to actively engage students. Collis and Bourguignon [22] also presented similar findings. When online MCQ exercises were given as formative assessments, many students regarded them as a way to help themselves to understand the course material and master relevant topics. Such 
findings also reveal that online MCQ exercises before year end tests or exams provide a positive learning environment for students and it implies that MCQ tests do help to cultivate habits that require independent learning as they evaluate their test performance. This brings us to the core issue of self-directed learning in this research. In his book, Knowles defines self-directed learning (SDL) as:

... a process in which individuals take the initiative, with or without the help of others, in diagnosing their learning needs, formulating learning goals, identifying human and material resources for learning, choosing and implementing appropriate learning strategies, and evaluating learning outcomes [23, p. 18].

He emphasizes that SDL does not mean "learning in isolation". On the contrary, SDL often takes place with the help of "teachers, tutors, mentors, resource people, and peers" [23]. Brockett and Hiemstra [24] continue that teachers in SDL environments should not act only as information providers, but also as facilitators that manage the teaching-learning process. For instance, facilitators can use supportive instructional devices to maintain students' interest in a particular subject matter.

Furthermore, learners' attitudes are also an important aspect of SDL. Knowles [23, p. 21] explains that when students go through the process of learning, their motivation to study comes from "external rewards and punishments," including "grades, diplomas, awards, degrees, and fear of failure." Self-directed learners' motivation to study often comes from "internal incentives", including "the need for esteem (especially self-esteem), the desire to achieve, the urge to grow, the satisfaction of accomplishment, the need to know something specific, and curiosity" [23, p. 21].

The importance of leaners' attitudes in SDL is also seen in the Personal Responsibility Orientation (PRO) model of SDL introduced by Brockett and Hiemstra [25]. In the PRO model, personal responsibility is the starting point of SDL. They [25] argue that the potential of an individual's self-direction is determined by his or her abilities and willingness to take control of his or her own learning. Hence, learner attitude constitutes a key criterion in SDL. Additionally, Garrison [26] noted that certain cognitive and metacognitive skills are also vital in SDL, which he claims are not addressed clearly in the PRO model. He clarifies that self-directed learners go into a process of developing their learning strategies and awareness as well as abilities to think about thinking. In other words, self-directed learners are responsible for self-monitoring their learning process, evaluating the outcomes, and constructing plans to achieve the intended outcomes as examples of the complex use of cognitive and metacognitive skills. In line with this argument, Brockett and Hiemstra [27] updated the PRO model to the Person-Process-Context (PPC) model. Under the 'person' element of the model, they [27] attest that critical reflection is one of the characteristics of self-directed learners. This means that in the PPC model, SDL learners are directed to reflect critically on their own learning process before and after constructing a learning plan or implementing a learning style.

Nicol [9] proposes the use of online MCQs as a support to develop learners' autonomy and selfregulation. Nicol and MacFarlane-Dick [28, p. 203] explain that one of the principles that facilitates selfregulation is it can "encourage positive motivation and self-esteem". Student motivation and self-esteem can be enhanced by using "low-stakes assessment tasks" that are designed to focus on students' progress and achievement rather than using "high-stakes summative assessment tasks" that focus solely on final marks [28, p. 212]. A low-stakes formative task will enable students to focus more on learning goals rather than final marks. In this way, educators can influence the ways students perceive the learning context, as Paris and Turner [29] argue, students' motivation is constructed by students themselves based on their own appraisal of the learning context. Therefore, students can be led to perceive a novel learning context, such as linking MCQs to an educational goal, like self-regulation. By giving MCQs in assessing the completion of lowstakes formative tasks that could have a bearing on the final summative assessments, MCQs become much more impactful on students' learning experience. Similarly, Abreu, Silva, and Gomes [30] found that MCQs increase students' motivation and performance. Students in their study reported that MCQs enabled them to get higher scores not because they could guess the answers, but because they could reflect on and learn about the topics better. Thus, students could examine each MCQ option and think deeper about each of the concepts involved. Hence, Abreu, Silva, and Gomes [30] concluded that MCQ increased students' satisfaction regarding their own learning experience.

The previous research provided an impetus into further investigation of SDL and use of online MCQs for language students in a university. One of the learning goals of the university is to imbibe in students the need to think critically, and also to develop greater self-independence as they transit from school to tertiary institution. This objective is very much in line with the Malaysia Education Blueprint 2015-2025 (Higher Education), which states that one focus of a higher learning institution (HLI) is "developing students to become more independent thinkers and self-learners" [31, p. 2]. 
In order to ensure that students become successful independent learners and thinkers, university students should be exposed to educational goals such as self-directed learning (SDL). Razali, Xuan, and Samad [32, p. 75] argue that SDL strategies should be included in the overall educational process because the "teacher-led context" is insufficient for students to become autonomous learners. Also, Razali, Xuan, and Samad [32] urge that traditional educational or paper-based formats be minimized in use as these methods hinder the potential of self-directed learners. Furthermore, as SDL approaches are incorporated within syllabuses, tasks, lessons and activities, "dependent learners (could) find a starting point to grasp autonomous learning" [32, pp. 75-76].

This research takes on the institutional and educators' challenge of providing students with opportunities or multiple attempts to develop SDL through weekly e-learning tasks. While the topics covered in these weekly e-learning tasks were connected with the topics students learned in class, students had to take charge of their own learning processes outside of classroom time. This research aims to look at how online MCQ exercises provided to students as weekly e-learning tasks outside of classroom time can promote SDL among university students. To guide the research, the following research question was formulated: To what extent do online MCQs with multiple attempts promote self-directed learning (SDL) among university students?

\section{RESEARCH METHOD}

In the university where the research was conducted, there were 6500 students were taking various courses (i.e., English, Mathematics, Engineering, Business, Economics, Psychology, Marketing). They were provided with different types of online exercises through the Blackboard Learning Management System (LMS) on a weekly basis, such as MCQs, fill in the blanks, discussing a particular topic using discussion forum, creating blog pages, and collaborating to manage wiki pages.

In June 2019 semester, two classes of a compulsory English course (i.e., Fundamentals of English) were opened. There were 60 students enrolled in this course, 39 of them were Diploma in Business students and 21 of them were Diploma in Accounting students. These 60 students were provided with two sets of online MCQ exercises through the Blackboard LMS every week for six weeks consecutively from June 2019 to July 2019.

The course structure of this compulsory English course was approved by Malaysian Qualifications Agency (MQA). The allocation of marks of this particular course is shown in Table 1. Any changes made to the allocation of marks need to be approved by MQA. As such, the online MCQ exercises do not carry any marks so as not to disturb the stated MQA document.

Table 1. Fundamentals of English's assessment methods and types

\begin{tabular}{ccc}
\hline Method & Types & Weightage (\%) \\
\hline & Assignment 1 & 10 \\
& Assignment 2 & 10 \\
Continuous assessment & Test 1 & 15 \\
& Test 2 & 15 \\
& Oral presentation & 10 \\
Summative assessment & Final examination & 40 \\
\hline
\end{tabular}

The stated learning outcomes of this course included the abilities to construct sentences using correct tenses, read and identify main ideas and supporting details, and being able to listen and respond appropriately. Hence, the provided online MCQ exercises ranged from grammar practices and reading comprehension to listening practices, as shown in Table 2. Each of the online MCQ exercises was linked to a particular learning outcome of the course.

To illustrate each of the online MCQ exercises stated in Table 2, some example items are attached in Appendix A. In answering all these MCQs, students have to apply grammar rules, reading skills and listening skills. This study is not designed with a view to test a difference between theoretical and practical exercises. 
Table 2. Online MCQ exercises provided to students

\begin{tabular}{ccc}
\hline Week & Provided online MCQ exercises & Total number of questions \\
\hline 1 & Parts of speech & 30 \\
& Listening practice & 20 \\
2 & Subject-verb agreement & 30 \\
& Present simple and present continuous tenses & 30 \\
3 & Model verbs: Must, need to, have to, and should & 30 \\
& Past simple and past continuous tenses & 30 \\
4 & Past simple and present perfect tenses & 30 \\
5 & Multiword verbs & 30 \\
& Geading comprehension & 20 \\
6 & Going to, present continuous tense and verbs about future plans & 30 \\
& Reported speech & 30 \\
\end{tabular}

Before the students pursue the course, they were told that the scores of these online MCQ exercises would not contribute to their final coursework marks. The main purpose of the exercises was to provide opportunities for students to understand and apply what they had learned in class. Therefore, the exercises were only available to students on Blackboard LMS after the topics had been taught in class. Students then had to complete two sets of online MCQ exercises outside of classroom time on a weekly basis. For each MCQ grammar practice, the questions were arranged in an order of difficulty to help students to revise the grammar rules learned to ease progressive learning. This staged approach also hoped to bring students away from a test taking mentality. For listening and reading practices, the set of questions were arranged according to the sequence of the information provided in the podcasts and reading texts to facilitate students in arriving at the answers.

For each set of online MCQ exercises, each student was allowed three attempts to complete the exercises. No matter how many times each student took to complete each set of MCQ exercises, the score recorded was the score of the final attempt. They were allowed to refer to slides or notes provided as well as search for more information online when they were doing the online MCQ exercises. However, the correct answers for all the questions were only revealed after the due dates for submission. As a result, students were not able to memorize answers or copy from each other with the view of getting correct answers.

\subsection{Instrument and method}

To elicit data, this research employed an exploratory sequential design, where qualitative data collection used focus group interviews, upon which the data was analysed. This was followed by quantitative data collection in the form of a survey questionnaire. Thereafter, the responses to the survey questionnaire were analysed and augmented by the qualitative data.

After students had completed 12 online MCQ exercises in six weeks, the first stage of the exploratory sequential design was carried out. Creswell and Clark [33] claim that adopting an exploratory sequential design enables researchers to generalize qualitative results collected from the first stage before applying it to a bigger sample in the second stage. Hence, in order to collect sufficient data that is neither biased nor misleading, but can be generalized later, this research interviewed almost half of the total number of participants involved. Thirty-three (33) out of 60 students were randomly selected to participate in focus group interviews.

Before embarking on this project, the researchers observed that, in comparison to students taking other English courses, students who took the course, Fundamentals of English, seemed to be more motivated to self-study using the exercises provided on Blackboard LMS. While students taking Fundamentals of English course were provided with two sets of online MCQ exercises through the Blackboard (LMS) on a weekly basis, students taking other English courses were provided with a range of exercises in the form of discussion board, blog, and wiki through Blackboard LMS on a weekly basis. Due to this difference, researchers would like to find out to what extent and how the online MCQ exercises provided have driven students to be motivated or have taken the initiative to self-study. Krueger and Casey [34] postulate that focus group interviews can help researchers to understand subject matter that is related to behaviour or motivation. Also, focus group interviews should be employed when researchers are looking for feelings, ideas, perceptions or opinions people have about a particular practice, program or idea [34]. Thus, in order to explore how the online MCQ exercises motivated students to experience self-study, the researchers began by qualitatively exploring this phenomenon in depth through focus group interviews. In other words, focus group interviews enable researchers to collect qualitative data which when generalized can also be helpful for developing a questionnaire that can be applied to a bigger sample in another stage of data collection. With this affirmation, this research employed focus group interviews as a method of data collection. 
In "Deciding on the number of groups", Morgan [35] mentioned that the typical number of focus groups is between three and five. More importantly, Hennink, Kaiser, and Weber [36] found that four focus groups are sufficient to identity the range of issues present. Thus, in this research, four focus group interviews were conducted. Since the group size recommended by Morgan [37] in "Deciding on group size" is between six and ten participants, the 33 participants were divided into four groups according to the recommended group size. The number of participants in each of these focus group interviews were eight, ten, six and nine respectively. The group size was not controlled as the students choose the time for the interviews based on a schedule given.

Each focus group interview used a semi-structured questioning approach. Before each focus group interview, participants were provided a brief explanation about the research. Moderators emphasized that there were no right or wrong answers to the questions asked, all opinions, perspectives, and ideas were appreciated. Also, moderators reassured that all information was kept confidential. All the four focus group interviews used the same interview guide (Appendix B), which was created following the guidelines proposed by Krueger and Casey [34] in Focus Groups: A Practical Guide for Applied Research as well as Rubin and Rubin [38] in Qualitative Interviewing: The Art of Hearing Data.

During the focus group interviews, participants were asked to comment on and discuss their experiences as they practiced what they had learned in the classroom by completing online MCQ exercises with multiple attempts outside of classroom time using Blackboard LMS. Participants were encouraged to provide examples to support or validate their statements. As mentioned by Krueger and Casey [34], focus group interview that has a focused discussion places the attention on understanding the participants' thoughts, comments and feelings, and the moderator does not pressure the group to come to an agreement. Thus, in all four focus group interviews, participants were encouraged to share their experiences with each other. For example, participants who had totally different experiences were encouraged to voice their views. At the end of each focus group interview, researchers summarized the statements made by participants and allowed participants to revise the summaries for accuracy. They can also clarify their statements or provide additional relevant information. Excluding the amount of time taken to explain the procedure and collect demographic information, each focus group interview took about an hour.

After analysing the qualitative data, researchers develop a questionnaire based on the qualitative results. Then, an online survey was administrated to further validate the findings of the interviews. The survey was conducted principally to determine students' SDL readiness in relation to the experience of completing the online MCQ exercises provided. For example, some of the questions asked were "I usually take the first attempt of the MCQ exercises as a self-evaluation of my current understanding of the topics covered in the MCQ exercises", "I complete the MCQ exercises because I WANT to, not because I HAVE to", and "I see the scores I get from the MCQ exercises as my learning progress." Students completed the online questionnaire with responses on a five-point Likert scale ranging from strongly disagree " 1 " to strongly agree " 5 " in July 2019. Table 3 summarises the design of the study.

Table 3. Research design

\begin{tabular}{lll}
\hline \multicolumn{1}{c}{ Research question } & \multicolumn{1}{c}{ Instrument } & \multicolumn{1}{c}{ Data analysis } \\
\hline To what extent do online MCQs with & Online survey questionnaire & Percentage, means, standard \\
multiple attempts promote self-directed & Part 1: Demographic information & deviation, t-test \\
learning (SDL) among students? & Part 2: SDL readiness (Adapted from [39], [40]) & Thematic analysis \\
\hline
\end{tabular}

\subsubsection{Reliability of the survey questionnaire}

To ensure internal consistency of the survey questionnaire items, Cronbach Alpha was calculated. An index of 0.97 was obtained. According to Fraenkel, Wallen, and Hyun [41], a Cronbach Alpha reading of an instrument has to be higher than 0.70 to be considered as reliable. Since the Cronbach Alpha reading is 0.97 , it suggests that the survey questionnaire is highly reliable.

\subsubsection{SDL readiness cut-off points}

This study employed a five-point Likert Scale in the survey. In order to report the results meaningfully, cut off points for SDL were determined. A simple guideline of using a mid-point response was used resulting in setting the benchmarks at the mid score of 3.00. As shown in Figure 1, items with means above 3.00 will be considered as having high SDL readiness, whereas items with means below 3.00 will be considered as having low SDL readiness. The binary division allows for a range of scores from 1.00 to 2.99 as indicators of low SDL readiness, while 3.00 and above will indicate a range of high SDL readiness. 


\section{RESULTS AND DISCUSSION}

Results from the online survey are tabulated in Table 4. From Table 4, it is evident that the means of all 20 items are above the cut-off point of 3.00 except Items 10 and 12. This is also reflected in the overall mean of the items which is 3.38. This suggests that the online MCQ questions in general were encouraging students to be self-directed learners. Standard deviations were narrow which revealed stability in responses.

Table 4. Descriptive analysis of survey items $(\mathrm{N}=60)$

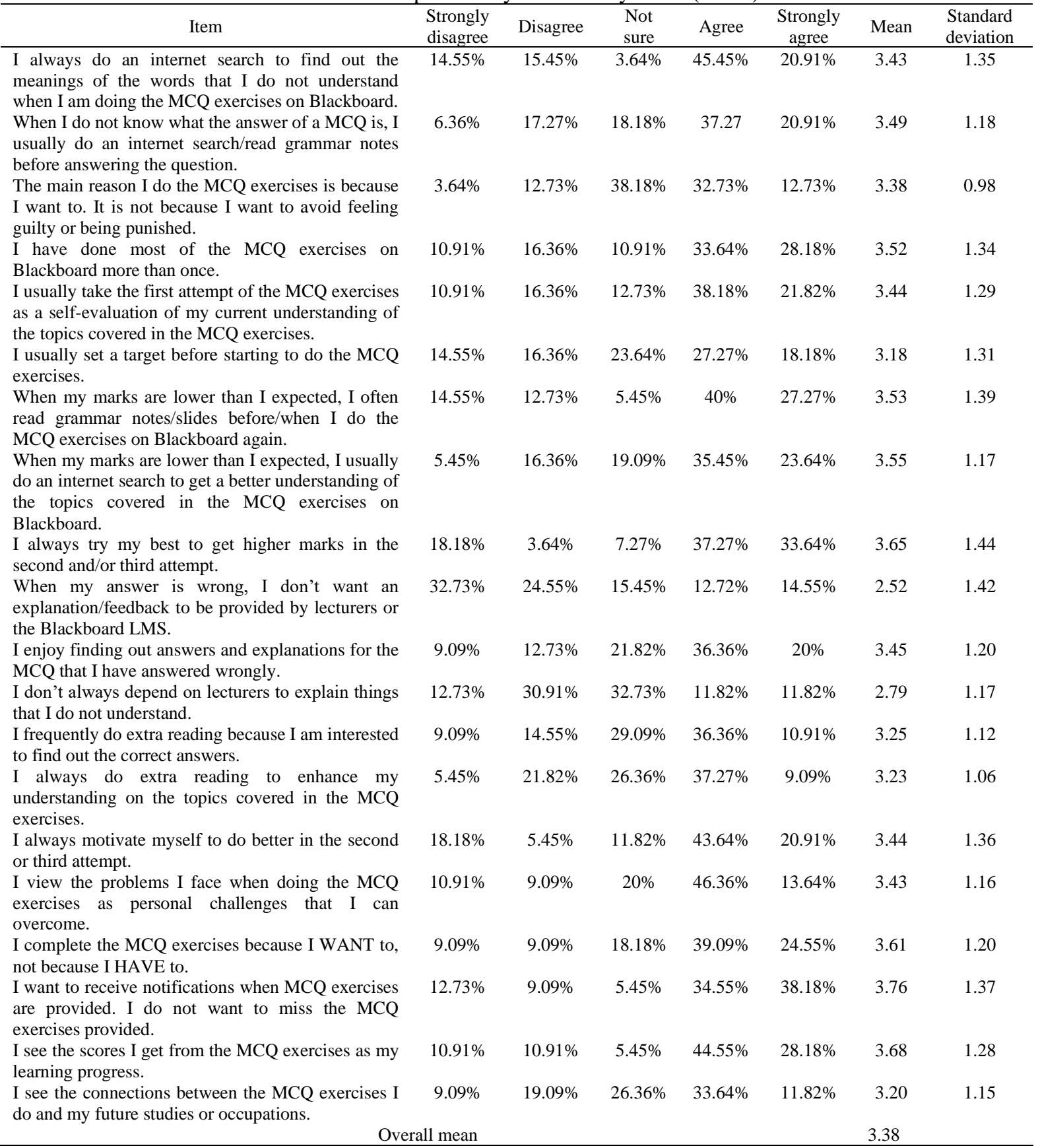


The 20 items used in this study can be categorised into two domains: Learners' Characteristics (LC) and Teaching and Learning (TL) features. Similar categorisation was also found in Stockdale's [39] research. According to Brockett and Hiemstra [25], both LC and TL are important constructs to demonstrate selfdirection. The items for LC suggest learners' beliefs, characteristics and attitudes in relation to taking own responsibility towards the learning process. TL items demonstrate learners' agreement with the process of organizing, executing and evaluating the learning process [39]. The items under LC are Item 3, 17, 19 and 20, whereas the remaining items are under TL. The means for both domains were calculated and t-test was done to find the significant difference between the two domains.

Table 5 shows that the mean of LC is 3.4682 whereas the mean of TL is slightly lower which is 3.3534. To find the significant difference between the two domains, a two-sample t-test with unequal variances $(\alpha=0.05)$ was conducted. The t-test indicates that there is no significant difference between the two components $(\mathrm{t}(6)=0.8504, \mathrm{p}=0.4277)$. This shows that one domain is not more dominant than the other in terms of its relationship with self-directed learning.

\begin{tabular}{lcc}
\multicolumn{3}{c}{ Table 5. T-test results } \\
\hline & LC & TL \\
\hline Mean & 3.4682 & 3.3534 \\
Variance & 0.0483 & 0.0983 \\
P & 0.4277 & \\
\hline
\end{tabular}

From the results of the current study, we could surmise that the use of online MCQ exercises with multiple attempts are able to: 1) Motivate students to take responsibility of their learning process; 2) Drive students to bridge the gap between their perceived challenges and their own abilities; 3) Prompt students to monitor their learning progress and generate suitable learning strategies; and 4) Encourage students to become active learners. The conclusions enable the researchers to make several claims that MCQs can help to develop self-directed learning in a meaningful and constructive manner far beyond the confines of the mere attainment of knowledge as a cognitive process.

\subsection{Online MCQ exercises with multiple attempts motivate students to take responsibility of their learning process}

Items that have high SDL mean scores include Items 1, 2, 4, 5, 7, 8, 9, 11, 15, 16, 17, 18 and 19. The mean scores of these items reflected that when students were doing the online MCQ exercises, most of them were practicing to be self-directed learners. For example, Item 18, which had the highest mean score $(M=3.76)$, revealed that most of the students did not want to miss out on the practice of doing the online MCQ exercises. This was further supported in the interview when a number of participants expressed their concern about missing out the given online MCQ exercises. In the focus group interview, one of the participants said:

\section{"I don't get notifications on my phone. Regularly I have to check it if the lecturer has started} the quiz or not."

Another student commented in the focus group interview:

"The time of the MCQs can extend or not? I sometimes do assignment until I forget the time already, I miss the questions."

As stated, students were aware that the scores of the online MCQ exercises were not taken into account in the final coursework marks. With this premise, we could infer that students were not likely to be worried about losing marks if they had overlooked the online MCQ exercises. The finding clearly shows that most of the students were enthusiastic about putting what they had learned in class into firm practice. This is further reinforced by the mean scores of Items $9(\mathrm{M}=3.65)$ and Item $17(\mathrm{M}=3.61)$. Results for Item 9 revealed that the online MCQ exercises with multiple attempts had motivated students to be high achievers by getting higher scores through their second and/or third attempts. This result corresponds with Abreu, Silva, and Gomes's [30] finding that MCQs can be a motivational factor for students. Abreu, Silva, and Gomes [30] reported that their students delineated MCQs had enabled them to increase their own satisfaction levels regarding their own learning, which in turn enabled them to get higher scores. Abreu, Silva, and Gomes [30] then concluded that MCQs could increase students' performance and motivation levels. Likewise, Item 17 
shows that most students completed the online MCQ exercises not because these exercises were designated as homework, but because they wanted to learn, and they viewed the exercises as opportunities to practice what they had learned. In other words, Item 17 signifies that the online MCQ exercises with multiple attempts were able to influence students to willingly take charge of their learning process.

\subsection{Online MCQ exercises with multiple attempts drive students to bridge the gap between their perceived challenges and their own abilities}

Moreover, Item 19 also has a mean score $(M=3.68)$ indicating high SDL readiness. This item could mean that many students viewed the scores they got from the online MCQ exercises as reflections of their own learning progress. This result reflected that students were evaluating their own performance using the online MCQ exercises. Surprisingly, Item 5, with a mean score of 3.44, shows that students had already started to evaluate their performance as they engaged with their first attempt for each set of the online MCQ exercises. This indicates that many of these students took the first attempt of the MCQ exercises as a selfevaluation of their current understanding of the topics covered in the exercises. It could also be said that students who obtained low scores were motivated to improve rather than be affected by a negative selfevaluation of their abilities. Item $15(\mathrm{M}=3.44)$ reveals that when students did not do well in the first attempt, they would try to do better in the second and third attempts. Students even commented during the focus group interviews that the three attempts given were not enough. One of the students commented: "The Blackboard exercises can only do three times, not enough." Another student suggested: "Seriously, really not enough. Five times la." Another student even suggested: "Unlimited is better."

As students repeated the same online MCQ exercises, students learned from their own mistakes and felt more confident when they got higher scores. Nicol [9] explains that as students are given opportunities to do MCQs repeatedly, the students are given chances to close the gap between current and desired performance. In other words, online MCQs with multiple attempts allow students to bridge the gap between their perceived challenges and their perceived abilities. Indirectly, this situation also drives students to take initiatives in their learning process. Item 16, with a mean score of 3.43, discloses that students viewed the online MCQ exercises as a personal challenge that they could take on. As students were given multiple attempts to answer the same online MCQ exercises, they realized that getting higher scores was in their hands. They only needed to learn from their own mistakes and practice a few times more to get higher scores. Whether they wanted to do the online MCQ exercises more than once to get a better understanding of the topics covered and obtain higher scores solely depended on whether they were willing to spend time and effort into doing the second and third attempts. From the results, it could be surmised that students were able to gauge what they had to learn using their own initiatives.

\subsection{Online MCQ exercises with multiple attempts prompt students to monitor their learning progress and generate suitable learning strategies}

Furthermore, Item 8 , which yielded a mean score of 3.55, reflects that when students obtained lower scores than they expected, they usually did an internet search to get a better understanding of the topics covered in the online MCQ exercises. Similarly, Item 7 (M=3.53) indicates that when the students obtained scores that were lower than what they expected, they often read notes or slides before or when they did the online MCQ exercises again. During the focus group interview, a number of participants shared a similar experience mentioned by this participant:

When I see the marks, if it is too low, ... I will try again. But before I try, I will do revision, see first. And whenever I do Blackboard exercises, I will put my notes beside it. When I don't know, I will check.

These remarks show that online MCQ exercises, which allow students to see their scores instantly after they have completed each exercise, motivate them to repeat the exercises in order to obtain higher scores. More importantly, the auto-graded and instant result features of online MCQ exercises also created a learning environment that leads students to critically reflect on their own learning. Garrison [26] emphasizes the importance of cognitive and metacognitive processes in SDL. Garrison [26] explains both cognitive and metacognitive processes are manifested as self-monitoring responsibility. Self-monitoring responsibility indicates the need to construct meaning through critical reflection [26]. As students take up the responsibility of monitoring their own learning processes, they are able to reflect critically on these processes, evaluate their results and generate new approaches to achieve targeted results [26]. The opportunity of carrying out internet searches to get a better understanding of the topics covered in the online MCQ exercises or read notes or slides to get higher scores in their next attempts at the exercises also indicated that students were actually self-evaluating their results. In the event, they were obviously using various approaches to achieve 
the results they targeted. This translates into prompting students to critically reflect on the results they have achieved and adopted learning strategies that befit the task. Based on their critical reflections, students then likely constructed or changed their learning plans and attempted the exercises again to achieve expected outcomes.

As a result, most students completed the online MCQ exercises more than once, as shown by Item 4, which has a mean score of 3.52. The result for Item 4 needs to be considered in relation to Item 3, which has a low mean score of 2.62. The result of Item 3 reveals that the reason most students completed the online MCQ exercises was not because they felt guilty or scared of being punished. The findings confirmed that the online MCQ exercises with multiple attempts had encouraged students to critically reflect on their learning process and do the exercises more than once. The exercises thus also encouraged students to become selfdirected learners. This research confirms Douglas, Wilson, and Ennis's [14, p. 111] argument that MCQs are a helpful tool in developing students' abilities to "monitor, manage, and self-direct their learning".

\subsection{Online MCQ exercises with multiple attempts encourages students to become active learners}

Since the MCQ exercises were provided using an online platform, Blackboard LMS, students' SDL learning styles are found to be closely connected with their technological skills. The effects of the online learning environment on students' learning styles are clearly shown through Items 1 and 2 . Item 1, with a mean score of 3.43, indicates that students always performed internet searches to find the meanings of words that they did not understand in the MCQ exercises. This was corroborated in comments collected during the focus group interviews. One of the students commented: "I can copy the word and google it to find the meaning."

Likewise, Item 2, with a higher mean score of 3.49, reflects that when students did not know what the answer for a MCQ, they usually did an internet search or read notes before answering the question. For instance, during the focus group interview, a student said, "When I meet something I don't know, I can YouTube to learn it." Similarly, another student said, "When I don't understand, I can search it on the internet immediately."

These findings show that when students equipped with relevant technological skills, are emplaced in an online learning environment, they take the initiative to teach themselves. This supports Geng, Law, and Niu's [42] claim that in a blended learning environment, the technology readiness of students has a noticeable impact on their learning presence. Another feature of the online MCQ exercises that drives students to take the initiative to teach themselves is the establishing of an open-book learning environment. Honey and Marshall [43] find that MCQs facilitate inquiry-based learning, support student learning, and encourage students to become active learners. It appears that when MCQs are given an open-book learning environment, students are motivated to look for answers by reading notes or performing internet searches. Nicol [9] delineates that such situations allow students to self-assess and self-correct. Together with the availability of multiple attempts, the online MCQ exercises thus allow students to bridge the gap between their initial results and their targeted results as well as between their perceptions of their own abilities and the releasing of their actual potentials. This feature of online MCQ exercises with multiple attempts is also crucial in ensuring students enjoy doing the exercises. This situation is reflected through Item 11, which yielded a mean score of 3.45. Students enjoyed finding answers and explanations for the MCQs that they had answered wrongly. When students find such SDL activities enjoyable and satisfying, they are motivated to become better self-directed learners.

\section{CONCLUSION}

This research provided empirical evidence that online MCQ exercises with multiple attempts help to promote self-directed learning (SDL). In this research, the scores of all the provided online MCQ exercises with multiple attempts did not contribute to students' coursework marks. These online MCQ exercises were only homework for students to realise what they had learned in class into practice outside of classroom time. While the mean scores were not significantly high (4.00 and above) the results nonetheless, indicate that the students perceived the effort as creating a positive learning climate. They had enthusiastically revised on the topics covered in the exercises and tried to obtain higher scores by doing the same sets of online MCQs more than once. Students were motivated to make use of these online MCQ exercises as opportunities to enhance their understanding of the topics taught in class. Furthermore, the auto-graded and instant result features of the online MCQ exercises with multiple attempts also drove students to critically reflect on their own learning process. They self-monitored their learning process by evaluating their results and generating new approaches to achieve the results they targeted. Since students had multiple attempts to arrive at the targeted scores, they were less likely to be affected by their initial low grades and be demotivated. On the contrary, students' resilience was more likely to be strengthened. Also, as students obtained better results in the second 
and third attempts, they bridged the gap between their perceived challenges and actual abilities. As the online MCQ exercises with multiple attempts provided opportunities for students to bridge this gap, students became more willing to self-direct their learning and be more success oriented.

Moreover, the open-book as well as the online learning environment provided by the MCQ exercises led students to take initiatives to become more active learners. Students reported that they always conducted internet searches or read notes or slides when they encountered questions, they were unable to answer or words they did not understand. Taking the initiative to teach themselves is not only a characteristic of SDL, but it also makes students enjoy the self-directed learning process. Nevertheless, the online MCQ exercises with multiple attempts were not able to shift students from over-relying on lecturers, teachers or tutors for feedback. This 'dependence' could explain to some extent the bunching of mean scores within the range of 3.18 to 3.7 in their positive responses. Thus, it is recommended that this issue be the starting point for future research on the relationship between SDL readiness and online MCQ exercises with multiple attempts. Also, in light of this research being confined to one institution and limited sample size, future studies could include more respondents to produce more generalizable empirical results. Besides, future studies could also investigate to what extent the online MCQ exercises with multiple attempts help students to improve their final course performance. This can be done through comparing final grades of students obtained in the course with grades of students who did not experience the intervention. Finally, other control variables could be taken into consideration in future research, such as gender, year of study of students, and locality of research. Factor or regression analysis could then be pursued whereby the dimension of predictive validity of the SDL measure could be investigated.

\section{ACKNOWLEDGEMENTS}

This work was supported by INTI International University's research-related conference expenses.

\section{APPENDIX A}

\section{Samples of MCQ Exercises}

Week 1A Online MCQ Exercise: Parts of Speech

Choose the correct parts of speech for the underlined words.

1. Unfortunately, they haven't been paying on time recently.
a. Noun
b. Verb
c. Adjective
d. Adverb

2. Art lovers can visit the Metropolitan Museum of Art on the upper East side next to Central Park.
a. Noun
b. Verb
c. Adjective
d. Adverb

Week 1B Online MCQ Exercise: Listening Practice

Listen to the podcast and choose the best answer.

1. When does Waldorf School of the Peninsula introduce screens to children?
a. Sixth grade
b. Seventh grade
c. Eighth grade
d. Ninth grade

2. Which of the following has stopping cues?
a. YouTube
b. Facebook
c. Instagram
d. Newspaper

Week 2A Online MCQ Exercise: Subject-Verb Agreement Choose the best answer for each of the questions.

1. Much of the machinery on these farms unusable.
a. am
b. is 
c. are

2. As most sports magazines can attest, playing sports such as tennis and basketball not only mental ability but also physical strength.
a. require
b. requires

Week 2B Online MCQ Exercise: Present Simple and Present Continuous Tenses

Choose the best answer for each of the questions.

1. Sound at about 340 metres per second.
a. travel
b. travels
c. is travelling
d. are travelling

2. Helen usually
a. work, watch
b. works, watches
c. works, is watching
d. is working, watches

Week 3A Online MCQ Exercise: Modal Verbs: Must, Need to, Have to, and Should Choose the best answer for each of the questions.

1. Mary: I'm not feeling so well. I've been having fever on and off, and my back is killing me. June: You see a doctor to make sure you're okay.
a. should
b. have
c. need
d. must to

2. Jamie: What is the time now?

John: 9am. Our class is at $12 \mathrm{pm}$. We get up now. We can sleep for 1 more hour.
a. shouldn't
b. have to
c. don't need to
d. mustn't

Week 3B Online MCQ Exercise: Past Simple and Past Continuous Tenses

Choose the best answer for each of the questions.

1. I Brad Pitt when I on Oxford Street
a. saw, shopped
b. saw, was shopping
c. was seeing, shopped
d. was seeing, was shopping

2. While the children
a. slept, watched
b. slept, were watching
c. were sleeping, watched
d. were sleeping, were watching

Week 4A Online MCQ Exercise: Past Simple and Present Perfect Tenses

Choose the best answer for each of the questions.

1. $\mathrm{He}$ in London for two years and then he to Cambridge.
a. lived, went
b. lived, has gone
c. has lived, has gone
d. has lived, has went

2. I can't play computer games because I
a. didn't finish
b. have not finish
c. has not finished
d. have not finished 
Week 4B Online MCQ Exercise: Multiword Verbs

Choose the best answer for each of the questions.

1. On the company's opening ceremony, half the guests failed to
a. turn on
b. turn up
c. turn off
d. turn down

2. He told the employee to go home and his offer.
a. go over
b. get over
c. talk over
d. think over

Week 5A Online MCQ Exercise: Reading Comprehension

Read the passage and answer all the questions.

1. All of the following statements are correct, except

a. Sumatran is the smallest of the nine original subspecies.

b. Sumatran male tigers usually grow less than eight feet long.

c. Matthew Luskin works as a research follow at National University of Singapore.

d. Sumatran tigers are losing their habitat as rain forest are turning into palm oil plantation.

2. "Flying over Sumatra is like flying over an ocean of oil palm plantations," adds co-author Mathias Tobler, a scientist with San Diego Zoo Global.

What can we infer from the sentence above?
a. There is an ocean in Sumatra.
b. There are a lot of palm trees in Sumatran.
c. The Sumatran Ocean is polluted by palm oil.
d. Mathias fly from San Diego to Sumatra to see the oil palm plantations.

Week 5B Online MCQ Exercise: Going to, Present Continuous Tense and Verbs about Future Plans Choose the best answer for each of the questions.

1. Papzi is a famous carbonated drinks company. Papzi to double the size of its sales to Malaysia's upper middle class.
a. will
b. will be
c. is hoping
d. is wanting

2. All the events for tomorrow's ceremony has been planned. Jennifer at the beginning of the ceremony.
a. sings
b. will sing
c. is singing
d. are singing

Week 6A Online MCQ Exercise: Reported Speech

Change the direct speech into reported speech.

1. Julie asked Katie, "Where do you work?"
a. Julie asks Katie where she works.
b. Julie asks Katie where does she work
c. Julie asked Katie where she worked.
d. Julie asked Katie where did she work.

2. Leslie asked Donald, "Will you be able to come to my wedding?"
a. Leslie asked Donald whether he will be able to come to his wedding.
b. Leslie asked Donald whether he would be able to come to his wedding.
c. Leslie asks Donald whether he will be able to come to his wedding.
d. Leslie asks Donald whether he would be able to come to his wedding. 
Week 6B Online MCQ Exercise: Conditionals

Choose the best answer for each of the questions.

1. Romeo is a chain-smoker.
a. If Romeo smoking, he healthier.
b. quits, will be
c. quitted, will be
d. quitted, would be
e. had quitted, would have been

2. James overslept this morning, and he missed the bus. If James__ this morning, he
a. does not oversleep, will not miss
b. did not oversleep, would not missed
c. has not overslept, would not have missed
d. had not overslept, would not have missed

\section{APPENDIX B}

\section{Interview Guide}

This guide is divided into four sections:

Section A: Icebreakers

1. How old are you?

2. Where did you have your primary and secondary education?

3. Please describe the types of English language exercises you had done during your primary and secondary education.

Section B: Transition questions

1. When did you start using software/ internet-based applications/ learning management system to do English language exercises?

2. From primary to secondary education and until now in university, what is your favourite form of English language exercises?

3. Apart from Blackboard LMS used in this course, what are the software/ internet-based applications/ learning management system you have used to do English language exercises?

Section C: Main questions

1. What do you think of /How do you feel about the online MCQ exercises provided to you on Blackboard LMS?

2. What do you like best about the online MCQ exercises provided to you on Blackboard LMS?

3. What are the things you do not like about the online MCQ exercises provided to you on Blackboard LMS?

4. Think back to a time when you completed a set of online MCQ exercise provided to you on Blackboard LMS, how did you feel about yourself when you completed the exercise?

5. Think back to a time when you did not complete the online MCQ exercises provided to you on Blackboard LMS, how did you feel?

6. Think back to a time when you were unhappy or angry or frustrated with the online MCQ exercises provided to you on Blackboard LMS, what were the problems you faced?

7. Think back to a time when you completed the online MCQ exercises provided to you on Blackboard LMS more than once (maybe twice/ three times), what motivated/ encouraged you to do the exercises more than once?

8. Think back to a time when you could/ should have done the online MCQ exercises provided to you on Blackboard LMS, but you did not you do it. What prevented you from completing the exercises?

Section D: Concluding question

Is there anything else you would like to say/ share about the online MCQ exercises provided to you on Blackboard LMS? 


\section{REFERENCES}

[1] C. Romero, M. I. López, J. M. Luna, and S. Ventura, "Predicting students' final performance from participation in on-line discussion forums," Comput. Educ., vol. 68, pp. 458-472, 2013.

[2] K. Mershad and P. Wakim, "A learning management system enhanced with internet of things applications," $J$. Educ. Learn., vol. 7, no. 3, pp. 23-40, 2018.

[3] S. Iqbal and I. A. Qureshi, "Learning management system (LMS): Inside matters," Inf. Manag. Bus. Rev., vol. 3, no. 4, pp. 206-216, 2011.

[4] D. Bauer, M. Holzer, V. Kopp, and M. R. Fischer, "Pick-N multiple choice-exams: A comparison of scoring algorithms," Adv. Heal. Sci. Educ., vol. 16, no. 2, pp. 211-221, 2011.

[5] R. M. S. H. B. Medawela, D. R. D. L. Ratnayake, W. A. M. U. L. Abeyasinghe, R. D. Jayasinghe, and K. N. Marambe, "Effectiveness of 'fill in the blanks' over multiple choice questions in assessing final year dental undergraduates," Educ. Medica, vol. 19, no. 2, pp. 72-76, 2018.

[6] R. Ranganath, C. Rajalaksmi, and M. A. Simon, "Medical students' perceptions of E-assessment: Multiple choice questions used as a tool of assessment for preclinical years," J. Med. Educ., vol. 16, no. 1, pp. 35-43, 2017.

[7] A. A. Vanderbilt, M. Feldman, and I. K. Wood, "Assessment in undergraduate medical education: A review of course exams," Med. Educ. Online, vol. 18, no. 1, pp. 1-5, 2013.

[8] A. A. Abbas, "An automatic system to grade multiple choice questions paper based exams," J. Univ. Anbar Pure Sci., vol. 3, no. 1, pp. 174-181, 2009.

[9] D. Nicol, "E-assessment by design: using multiple-choice tests to good effect," J. Furth. High. Educ., vol. 31, no. 1, pp. 53-64, 2007.

[10] C. G. Dascalu, A. M. Enache, R. B. Mavru, and G. Zegan, "Computer-based MCQ assessment for students in dental medicine - advantages and drawbacks," Procedia - Soc. Behav. Sci., vol. 187, pp. 22-27, 2015.

[11] L. W. T. Schuwirth and C. P. M. van der Vleuten, "ABC of learning and teaching in medicine: Written assessment," Br. Med. J., vol. 326, pp. 643-645, 2003.

[12] L. W. Anderson, D. Krathwohl, P. Airasian, K. Cruikshank, R. Mayer, P. Pintrich, et al., A taxonomy for learning, teaching, and assessing: A revision of Bloom's taxanomy of educational objectives, Abridged Edition. New York: Longman, 2001.

[13] B. S. Bloom, M. D. Engelhart, E. J. Furst, W. H. Hill, and D. R. Krathwohl, Taxonomy of educational objectives: The classification of educational goals. Handbook I: Cognitive domain. London: Longmans, Green and Co Ltd, 1956.

[14] M. Douglas, J. Wilson, and S. Ennis, "Multiple-choice question tests: A convenient, flexible and effective learning tool? A case study," Innov. Educ. Teach. Int., vol. 49, no. 2, pp. 111-121, 2012.

[15] M. G. Simkin and W. L. Kuechler, "Multiple-choice tests and student understanding: What is the connection?" Decis. Sci. J. Innov. Educ., vol. 3, no. 1, pp. 73-97, 2005.

[16] S. Buckles and J. J. Siegfried, "Using multiple-choice questions to evaluate in-depth learning of economics," $J$. Econ. Educ., vol. 37, no. 1, pp. 48-57, 2006.

[17] J. C. Masters, B. S. Hulsmeyer, M. E. Pike, K. Leichty, M. T. Miller, and A. L. Verst, "Assessment of multiplechoice questions in selected test banks accompanying text books used in nursing education," J. Nurs. Educ., vol. 40, no. 1, pp. 25-32, Jan. 2001.

[18] P. McKenna, "Multiple choice questions: Answering correctly and knowing the answer," Interact. Technol. Smart Educ., vol. 16, no. 1, pp. 59-73, 2019.

[19] K. Scouller, "The influence of assessment method on students' learning approaches: Multiple choice question examination versus assignment essay," High. Educ., vol. 35, pp. 453-472, 1998.

[20] K. A. Cobb, G. Brown, D. A. D. C. Jaarsma, and R. A. Hammond, "The educational impact of assessment: A comparison of DOPS and MCQs," Med. Teach., vol. 35, no. 11, pp. e1598-e1607, 2013.

[21] J. Dalziel and S. Gazzard, "The future of multiple choice questions in learning: Formative assessment, interactive teaching modules and student-created questions within WebMCQ," in Proceeding of Tools for Flexible Learning Workshop, 1999, pp. 20-22.

[22] N. Collis and J. Bourguignon, "Students' perceptions of online MCQs: Gathering evidence and learning to swim with it," in ALT Annual Conference, 2014.

[23] M. S. Knowles, Self-directed learning: A guide for learners and teachers. Englewood Cliffs: Cambridge Adult Education, 1975.

[24] R. G. Brockett and R. Hiemstra, "Bridging the theory-practice gap in self-directed learning," New Dir. Adult Contin. Educ., no. 25, pp. 31-40, 1985.

[25] R. G. Brockett and R. Hiemstra, Self-direction in adult learning: Perspectives on theory, research, and practice. London and New York: Routledge, 1991.

[26] D. R. Garrison, "Self-directed learning: Toward a comprehensive model," Adult Educ. Q., vol. 48, no. 1, pp. 18-33, 1997.

[27] R. Hiemstra and R. G. Brockett, "Reframing the meaning of self-directed learning: An Updated Modeltt," in Adult Education Research Conference Proceedings, 2012, pp. 155-161.

[28] D. Nicol and D. MacFarlane-Dick, "Formative assessment and self-regulated learning: A model and seven principles of good feedback practice," Stud. High. Educ., vol. 31, no. 2, pp. 199-218, 2006.

[29] S. G. Paris and J. C. Turner, "Situated motivation," in P. R. Pintrich, D. R. Brown, and C. E. Weinstein, Eds., Student motivation, cognition, and learning: Essays in honor of Wilbert J. McKeachie. Lawrence Erlbaum Associates, Inc., 1994, pp. 213-237. 
[30] P. H. Abreu, D. C. Silva, and A. Gomes, "Multiple-choice questions in programming courses: Can we use them and are students motivated by them?" ACM Trans. Comput. Educ., vol. 19, no. 14, pp. 6:1-6:16, 2018.

[31] Ministry of Education Malaysia. Malaysia education blueprint 2015-2025 (higher education), 2015.

[32] A. B. Razali, L. Ying Xuan, and A. A. Samad, "Self-directed learning readiness (SDLR) among foundation students from high and low proficiency levels to learn English language," Malaysian J. Learn. Instr., vol. 15, no. 2, pp. 55-81, 2018.

[33] J. W. Creswell and V. L. Plano Clark, "Choosing a mixed methods design," in Designing and Conducting Mixed Methods Research, 2nd ed. Thousand Oaks, California: Sage Publications, Inc., 2011, pp. 53-106.

[34] R. A. Krueger and M. A. Casey, Focus groups: A practical guide for applied research, 5th ed. London: Sage Publications, Inc., 2015.

[35] D. L. Morgan, "Deciding on the number of groups," in Focus Group kit 2: Planning Focus Groups. Thousand Oaks, California: SAGE Publications, Inc., 1998, pp. 77-84.

[36] M. M. Hennink, B. N. Kaiser, and M. B. Weber, "What influences saturation? Estimating sample sizes in focus group research," Qual. Health Res., vol. 29, no. 10, pp. 1483-1496, 2019.

[37] D. L. Morgan, "Deciding on group size," in Focus Group kit 2: Planning Focus Groups. Thousand Oaks, California: SAGE Publications, Inc., 1998, pp. 71-76.

[38] H. J. Rubin and I. S. Rubin, Qualitative interviewing: The art of hearing data, 3rd ed. Thousand Oaks, California: Sage Publications, Inc., 2012.

[39] S. L. Stockdale, "Development of an instrument to measure self-directedness," University of Tennesse, 2003.

[40] W. Q. Shen, H. L. Chen, and Y. Hu, "The validity and reliability of the self-directed learning instrument (SDLI) in mainland Chinese nursing students," BMC Med. Educ., vol. 14, no. 1, pp. 1-7, 2014.

[41] J. R. Fraenkel, N. E. Wallen, and H. H. Hyun, How to design and evaluate research in education, 8th ed. New York: McGraw-Hill, 2012.

[42] S. Geng, K. M. Y. Law, and B. Niu, "Investigating self-directed learning and technology readiness in blending learning environment," Int. J. Educ. Technol. High. Educ., vol. 16, no. 17, pp. 1-22, 2019.

[43] M. Honey and D. Marshall, "The impact of on-line muti-choice questions on undergraduate student nurses' learning," in Proceedings of the 20th Annual Conference of the Australasian Society for Computers in Learning in Tertiary Education (ASCILITE), 2003, pp. 236-243. 